OESOPHAGUS

\title{
Cure of Helicobacter pylori infection in patients with reflux oesophagitis treated with long term omeprazole reverses gastritis without exacerbation of reflux disease: results of a randomised controlled trial
}

\author{
E J Kuipers, G F Nelis, E C Klinkenberg-Knol, P Snel, D Goldfain, J J Kolkman, H P M Festen, J Dent, \\ P Zeitoun, N Havu, M Lamm, A Walan
}

Gut 2004:53:12-20

See end of article for authors' affiliations

Correspondence to Professor E J Kuipers, Department of Gastroenterology and Hepatology, Erasmus MC University Medical Centre, PO Box 2040, 3000 CA

Rotterdam, the

Netherlands:

e.j.kuipers@erasmusmc.nl

Accepted for publication 27 May 2003

\begin{abstract}
Background: Helicobacter pylori gastritis may progress to glandular atrophy and intestinal metaplasia, conditions that predispose to gastric cancer. Profound suppression of gastric acid is associated with increased severity of $H$ pylori gastritis. This prospective randomised study aimed to investigate whether $H$ pylori eradication can influence gastritis and its sequelae during long term omeprazole therapy for gastrooesophageal reflux disease (GORD).

Methods: A total of $231 \mathrm{H}$ pylori positive GORD patients who had been treated for $\geqslant 12$ months with omeprazole maintenance therapy $(O M)$ were randomised to either continuation of OM (OM only; $n=120$ ) or $O M$ plus a one week course of omeprazole, amoxycillin, and clarithromycin (OM triple; $n=111$ ). Endoscopy with standardised biopsy sampling as well as symptom evaluation were performed at baseline and after one and two years. Gastritis was assessed according to the Sydney classification system for activity, inflammation, atrophy, intestinal metaplasia, and $\mathrm{H}$ pylori density.

Results: Corpus gastritis activity at entry was moderate or severe in $50 \%$ and $55 \%$ of the OM only and OM triple groups, respectively. In the OM triple group, $H$ pylori was eradicated in $90(88 \%)$ patients, and activity and inflammation decreased substantially in both the antrum and corpus $(p<0.001$, baseline $v$ two years). Atrophic gastritis also improved in the corpus $(\mathrm{p}<0.001)$ but not in the antrum. In the $83 \mathrm{OM}$ only patients with continuing infection, there was no change in antral and corpus gastritis activity or atrophy, but inflammation increased $(\mathrm{p}<0.01)$. H pylori eradication did not alter the dose of omeprazole required, or reflux symptoms.

Conclusions: Most $\mathrm{H}$ pylori positive GORD patients have a corpus predominant pangastritis during omeprazole maintenance therapy. Eradication of $\mathrm{H}$ pylori eliminates gastric mucosal inflammation and induces regression of corpus glandular atrophy. $\mathrm{H}$ pylori eradication did not worsen reflux disease or lead to a need for increased omeprazole maintenance dose. We therefore recommend eradication of $H$ pylori in GORD patients receiving long term acid suppression.
\end{abstract}

Abbreviations: GORD, gastro-oesophageal reflux disease; PPI, proton pump inhibitor; OM, omeprazole; OAC, omeprazole, amoxycillin, clarithromycin; OMC, omeprazole, metronidazole, clarithromycin therapy for gastro-oesophageal reflux disease (GORD) but these studies were uncontrolled..$^{11-14}$

The possibility that acid suppressive therapy accelerates the development of atrophy is clinically relevant because many GORD patients who are infected with $H$ pylori require maintenance proton pump inhibitor (PPI) therapy. The European Helicobacter pylori Study Group, among others, has therefore advised that $H$ pylori should be eradicated in GORD patients treated with PPI maintenance therapy. ${ }^{15}$ However, to date there are only limited data on whether this intervention substantially alters the pattern and severity of $H$ pylori associated gastritis during continued PPI therapy. ${ }^{16}{ }^{17}$ There have also been concerns that the adequacy of control of reflux disease by therapy could be impaired by $H$ pylori eradication. We therefore performed a prospective controlled trial which evaluated the effects of $H$ pylori eradication on changes in gastric histology and symptom control over two years, suppression were compared. Accelerated development of atrophy was concluded by Kuipers and colleagues ${ }^{9}$ but was not confirmed by Lundell and colleagues. ${ }^{10}$ Other cohort studies reported development of atrophic gastritis within several years of treatment with profound acid suppressive 
in $H$ pylori infected GORD patients already established on omeprazole maintenance therapy.

\section{METHODS}

\section{Study overview}

Eligible $H$ pylori infected patients were randomised to continued omeprazole treatment without $H$ pylori eradication (OM only) or continued omeprazole after a one week omeprazole based triple $H$ pylori eradication therapy (OM triple). Patients underwent endoscopy, biopsy, and clinical assessments at baseline, one year, and at study completion after two years. Patients and clinicians involved in the study remained blinded as to the $H$ pylori negativity of each individual throughout the study.

\section{Patients}

Patients were required to be at least 18 years old, have a history of GORD, and have been treated for at least 12 months with daily omeprazole maintenance therapy. GORD had to have been diagnosed by endoscopy, or by 24 hour oesophageal pH metry. Patients were excluded from the study if they had a history of complicated peptic ulcer disease or if they were known to have Zollinger-Ellison syndrome or another concomitant disorder which could interfere with the study assessment, such as severe cardiac, hepatic, or renal disease, or a suspected or confirmed malignancy. Patients who required continuous treatment with drugs that could interact with clarithromycin were also excluded. The protocol was approved by the ethics committees of the 42 participating centres in seven countries (see appendix). The majority of these centres were general hospitals. Informed written consent was obtained from each patient.

\section{Protocol}

All eligible patients underwent upper gastrointestinal endoscopy. Endoscopic findings were recorded systematically. Reflux oesophagitis was classified according to the Savary Miller system. ${ }^{18}$ Barrett's oesophagus was defined as the presence of cylindrical epithelium with intestinal metaplasia in the distal oesophagus over a distance of $3 \mathrm{~cm}$ or more, and hiatus hernia as extension of the gastric folds to at least $2 \mathrm{~cm}$ above the diaphragm impression. Biopsies for histology and $H$ pylori culture were taken with standard biopsy forceps from the antrum, $2 \mathrm{~cm}$ proximal to the pylorus $(\times 2)$, and from the corpus along the greater curvature $10 \mathrm{~cm}$ below the cardia $(\times 5)$. In the case of a Barrett's oesophagus or specific lesions, additional samples were obtained but these were not part of this study. Patients were considered to be $H$ pylori positive if either culture or histology, or both, showed infection in one or more samples. These patients were eligible for inclusion, and were randomised to either omeprazole alone (OM only group) or OM plus $H$ pylori eradication therapy given in the first week (OM triple group) (fig 1). Randomisation occurred at a ratio of $1: 1$ for each treatment arm, within blocks of four consecutive patients per participating centre. The allocation sequence was computer generated and distributed by the central study coordinator. Participants were enrolled and assigned to their study treatment by the local investigator. Eradication therapy consisted of a seven day course of omeprazole $20 \mathrm{mg}$ twice daily, amoxycillin $1000 \mathrm{mg}$ twice daily, and clarithromycin $500 \mathrm{mg}$ twice daily (OAC). Patients allergic to amoxycillin received omeprazole in combination with metronidazole $400 \mathrm{mg}$ twice daily and clarithromycin $250 \mathrm{mg}$ twice daily (OMC). After the first week, patients continued omeprazole at the dose they were using prior to inclusion in the study.

During follow up, adjustment of the dose of omeprazole was permitted on the basis of symptom status or endoscopic findings. Decisions on dose adjustment were left to the patient and treating physician. Comedication at any time was noted. At the one and two year follow up visits, endoscopy and biopsy were repeated. Patients scored their reflux symptom status for the seven days prior to inclusion and the follow up visits on a scale of $0-3$, representing: (0) no symptoms; (1) occasional episodes of reflux complaints but easily tolerated and not interfering with normal activities; (2) daily episodes and occasionally interfering with normal activities; and (3) daily episodes and constantly interfering with normal activities.

\section{Histological and culture methods}

Histological methods were as described previously. ${ }^{9}$ In brief, $5 \mu \mathrm{m}$ thick sections stained with haematoxylin-eosin were used for standard histological evaluation. $H$ pylori was detected by a modified silver impregnation method. ${ }^{19}$ Sevier-Munger silver staining, ${ }^{20}$ and sometimes Grimelius staining also, ${ }^{21}$ were used to detect argyrophil neuroendocrine cells (mainly enterochromaffin-like cells). Slides were encoded, scrambled, and stained together so that the pathologist was blinded to the timings of biopsies and the identity of the patient. The pathologist $(\mathrm{NH})$ was isolated from all participating centres and reviewed the encoded slides without any access to clinical or endoscopic data, timing of sampling, or previous results from the same patient. He graded the encoded samples according to the Sydney classification system. ${ }^{22}$ The following items were evaluated separately: $H$ pylori density, any acute inflammatory component of gastritis (especially the amount of neutrophil infiltration), chronic inflammatory gastritis (especially the amount of lymphoplasmacytic infiltration), gastric glandular atrophy on the basis of gland loss, and intestinal metaplasia. All of these items were scored from 0 (absent), to 1 (mild), 2 (moderate), or 3 (severe), as defined in the

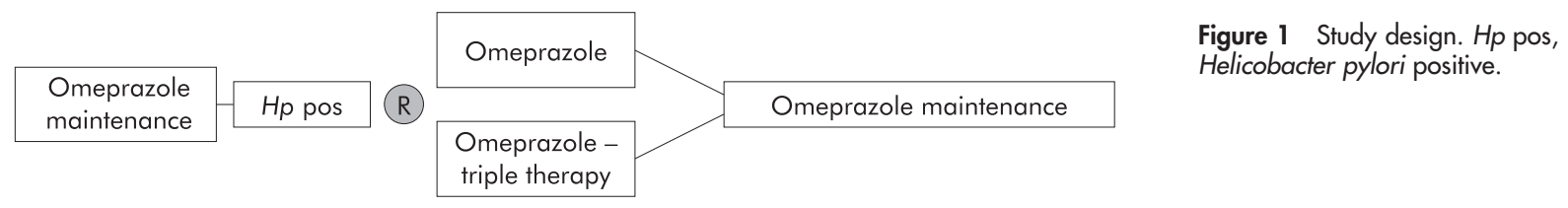

\begin{tabular}{|c|c|c|c|}
\hline & -14 days & & \\
\hline & Baseline & 12 months & 24 months \\
\hline Endoscopy & $\bigcirc$ & $\bigcirc$ & 0 \\
\hline Biopsy sampling & 0 & 0 & 0 \\
\hline Symptom score & 0 & 0 & 0 \\
\hline
\end{tabular}




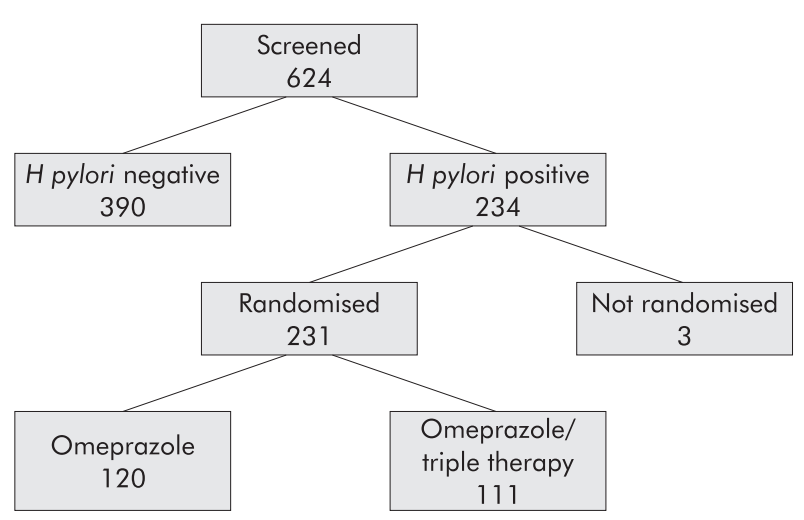

Figure 2 Patient flow chart.

Sydney classification system. The classification of Solcia et al was used to score the argyrophil cell pattern ${ }^{23}$; this ranges from normal (0) to diffuse (1), linear (2), or micronodular hyperplasia (3), and further includes adenomatoid hyperplasia, dysplasia, intramucosal neoplasm, and invasive neoplasm. Culture of $H$ pylori was performed under microaerophilic conditions using blood agar plates.

\section{Statistical analysis}

Statistical analysis was performed using Wilcoxon's rank sum test for changes from baseline to the last visit in terms of the number of severity grades. ${ }^{24}$ Two tailed $p$ values smaller than 0.01 were considered to indicate statistical significance. The main analysis was comparison of treatment arms, irrespective of the $H$ pylori status of individual patients during follow up. A secondary analysis compared outcomes in those patients in the OM triple group in whom $H$ pylori eradication had succeeded with those in the OM only group shown to remain $H$ pylori positive at the two year last visit. A sample size of 225 evaluable patients equally distributed over both groups was calculated to allow demonstration of a $10 \%$ difference in the proportion of patients with atrophic gastritis in both groups with an $85 \%$ test power.

\section{RESULTS}

\section{Patients}

In total, 624 potentially eligible GORD patients who met all of the criteria for randomisation and who had been treated for at least 12 months with omeprazole underwent screening endoscopy with biopsy sampling (fig 2). A total of 234 $(37.5 \%)$ of these patients were $H$ pylori positive. Because of error, three eligible patients were never randomised and were therefore excluded from further analysis. Of the remaining 231 patients (126 men and 105 women), 120 were randomised to OM only and 111 to OM triple. Of the latter, 100 received OAC and 11 OMC. The two randomised groups did not differ with respect to baseline characteristics (table l).

\section{Histology}

\section{Analysis according to treatment arm} Corpus

Baseline or follow up corpus biopsy specimens were unavailable for 11 patients in the OM only group and for nine patients in the OM triple group; hence complete data were available for 211 (109 v 102) patients.

Corpus gastritis activity was moderate to severe in $50 \%$ of patients in the OM only group at the start of the study and in $50 \%$ and $48 \%$ at one and two years, respectively (table 2 ). The OM triple group was strikingly different at two years, as moderate to severe gastritis was present in 55\% at baseline and in only $4 \%$ and $5 \%$ at one and two years, respectively.
Table 1 Baseline characteristics of the two groups (omeprazole alone (OM only) or OM plus $\mathrm{H}$ pylori eradication therapy given in the first week (OM triple))

\begin{tabular}{|c|c|c|}
\hline & $\begin{array}{l}\text { OM only } \\
(n=120)\end{array}$ & $\begin{array}{l}\text { OM triple } \\
(n=111)\end{array}$ \\
\hline $\operatorname{Sex}(M / F)$ & $72 / 48$ & $54 / 57$ \\
\hline \multicolumn{3}{|l|}{ Age $(y)$} \\
\hline Mean & 62.4 & 61.8 \\
\hline SD & 12.0 & 12.3 \\
\hline Min & 31 & 27 \\
\hline Max & 82 & 86 \\
\hline \multicolumn{3}{|c|}{$\begin{array}{l}\text { No of treatment years with } \\
\text { omeprazole at baseline }\end{array}$} \\
\hline Mean & 5.3 & 5.3 \\
\hline SD & 3.1 & 3.0 \\
\hline Min & 1.0 & 0.9 \\
\hline $\operatorname{Max}$ & 12.9 & 11.4 \\
\hline \multicolumn{3}{|c|}{ Omeprazole maintenance dose (mg) } \\
\hline Mean & 26.1 & 26.7 \\
\hline SD & 12.0 & 13.2 \\
\hline Min & 10.0 & 10.0 \\
\hline $\operatorname{Max}$ & 80.0 & 80.0 \\
\hline \multicolumn{3}{|c|}{ Duration of GORD (y) } \\
\hline $1-5$ & 30 & 26 \\
\hline $6-10$ & 25 & 26 \\
\hline$>10$ & 65 & 59 \\
\hline \multicolumn{3}{|c|}{ Hiatus hernia } \\
\hline Present & 52 & 44 \\
\hline \multicolumn{3}{|c|}{ Barrett's oesophagus } \\
\hline Present & 24 & 27 \\
\hline
\end{tabular}

This difference in the change in gastritis activity between the groups over the two years was highly significant $(\mathrm{p}<0.001)$.

Moderate to severe chronic inflammation was present in $69 \%$ of OM only patients at baseline and in $80 \%$ and $75 \%$ at one and two years (table 2). By comparison, moderate to severe chronic inflammation was observed in the OM triple group in $73 \%$ at baseline and in only $11 \%$ and $13 \%$ at one and two years (comparison between groups, $\mathrm{p}<0.001$ ).

Corpus glandular atrophy of any degree was present in $24 \%$ of the OM only group at baseline and in $23 \%$ at one and two years (fig 3). If only moderate to severe atrophy were considered, this was present in the OM only group in $11 \%$ at baseline and in $13 \%$ and $12 \%$ at one and two years, respectively. In the OM triple group, corpus mucosa atrophy of any degree was present in $27 \%$ of patients at baseline. In contrast with the lack of effect seen in the OM only group, the prevalence of atrophy of any severity decreased to $19 \%$ and $14 \%$, respectively, one and two years after $H$ pylori eradication therapy. The proportion of OM triple treated patients who had moderate to severe atrophy changed from $15 \%$ at baseline to $3 \%$ and $5 \%$ at one and two years, respectively (comparison between groups, $\mathrm{p}<0.001$ ) (table 2 ).

Corpus intestinal metaplasia was uncommon at baseline, and did not change in either group at two years (table 2). All cases of intestinal metaplasia were type I.

Corpus argyrophil cell hyperplasia did not change significantly over time in the OM only group, increasing from $20 \%$ at baseline to $29 \%$ at two years. In the OM triple group, the proportion of patients with argyrophil cell hyperplasia decreased significantly from $29 \%$ at baseline to $19 \%$ at two years $(\mathrm{p}<0.001)$. Argyrophil cell hyperplasia was significantly more common in patients with glandular atrophy; at two years hyperplasia was present in $31 / 41(76 \%)$ patients with glandular atrophy versus $21 / 173(12 \%)$ patients without atrophy $(\mathrm{p}<0.001)$.

Corpus dysplasia was found in one patient in the OM only group in the corpus biopsy at 12 months. Subsequent endoscopy with more extensive biopsy sampling confirmed 


\begin{tabular}{|c|c|c|c|c|c|c|}
\hline \multirow[b]{2}{*}{ Variable } & \multirow[b]{2}{*}{ Score } & \multicolumn{2}{|c|}{$\begin{array}{l}\text { OM only (by treatment } \\
\text { group) }\end{array}$} & \multicolumn{2}{|c|}{$\begin{array}{l}\text { OM triple (by treatment } \\
\text { group) }\end{array}$} & \multirow[b]{2}{*}{ p Value } \\
\hline & & Baseline & Last visit & Baseline & Last visit & \\
\hline \multirow{4}{*}{ Activity } & None & 16 & 25 & 12 & 92 & \multirow{4}{*}{$<0.001$} \\
\hline & Mild & 39 & 32 & 34 & 5 & \\
\hline & Moderate & 37 & 29 & 37 & 4 & \\
\hline & Severe & 17 & 23 & 19 & 1 & \\
\hline \multirow{4}{*}{ Inflammation } & None & 5 & 12 & 9 & 43 & \multirow{4}{*}{$<0.001$} \\
\hline & Mild & 29 & 15 & 19 & 46 & \\
\hline & Moderate & 52 & 45 & 51 & 11 & \\
\hline & Severe & 23 & 37 & 23 & 2 & \\
\hline \multirow[t]{4}{*}{ Atrophy } & None & 82 & 84 & 74 & 88 & \multirow{4}{*}{$<0.001$} \\
\hline & Mild & 15 & 12 & 13 & 9 & \\
\hline & Moderate & 7 & 7 & 11 & 5 & \\
\hline & Severe & 5 & 6 & 4 & & \\
\hline \multirow[t]{4}{*}{ Intestinal metaplasia } & None & 103 & 106 & 97 & 95 & \multirow{4}{*}{0.227} \\
\hline & Mild & 6 & 3 & 4 & 7 & \\
\hline & Moderate & & & 1 & & \\
\hline & Severe & & & & & \\
\hline \multirow{4}{*}{ H pylori } & None & 9 & 29 & 7 & 92 & \multirow{4}{*}{$<0.001$} \\
\hline & Mild & 34 & 18 & 32 & 1 & \\
\hline & Moderate & 21 & 18 & 15 & 4 & \\
\hline & Severe & 45 & 44 & 48 & 5 & \\
\hline
\end{tabular}

this and gastric resection revealed a $3 \times 3 \mathrm{~cm}$ T2 adenocarcinoma. No signs of recurrent or metastatic disease have been found in this patient at follow up.

Corpus $H$ pylori density at baseline was moderate or severe in about two thirds of patients in both treatment groups (table 2).

\section{Antrum}

Follow up antrum biopsy specimens were unavailable from 13 OM only and 15 OM triple patients. Accordingly, the data summarised in table 3 are for 203 (107 versus 96) patients.

Antral gastritis activity was predominantly mild or absent in both groups at baseline and did not change significantly over the two years of observation in the OM only group. The OM triple group showed a highly significant $(\mathrm{p}<0.001)$ virtual disappearance of antral activity at two years compared with the OM only group.

Antral chronic gastritis at baseline was highly prevalent for both groups, and remained so for the OM only group,

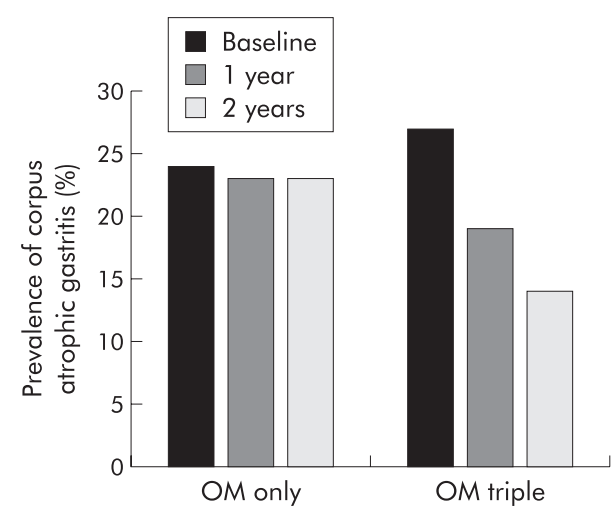

Figure 3 Prevalence of corpus atrophic gastritis in patients randomly assigned to omeprazole alone (OM only) or to eradication triple therapy (OM triple). The bars represent per cent corpus atrophic gastritis at baseline, and after one and two years of follow up for the OM only and OM triple group. although this was mild in slightly more than half of the patients. The OM triple group showed a substantial improvement in antral inflammation at two years $(\mathrm{p}<0.01)$.

Antral glandular atrophy did not change in either group over time and was moderate to severe in only $5 \%$ of patients at two years.

Antral intestinal metaplasia was also not influenced by $H$ pylori eradication but was present in $19 \%$ of patients at two years, with no differences between the groups.

Antral $H$ pylori density was either mild or could not be assessed because of absence of visible bacteria in the great majority of patients at baseline.

\section{Analysis according to $H$ pylori status}

At two years, 90 (88\%) OM triple patients and 29 (24\%) OM only patients had become $H$ pylori negative. Of the latter group, 10 were documented to have used antibiotics during follow up. Tables 4 and 5 show the data according to $H$ pylori status at two years for the subgroups of proven $H$ pylori negative OM triple patients and persistently $H$ pylori positive OM only patients. From a comparison with tables 2 and 3, it can be seen that changes in gastric histology over time in the $\mathrm{OM}$ only and $\mathrm{OM}$ triple groups were related to $H$ pylori status. In other words, patients in whom OM triple failed to eradicate $H$ pylori showed a similar persistence of chronic active gastritis during follow up as those treated with OM only. This contrasted clearly with patients in the OM only group who became $H$ pylori negative in whom there was a similar improvement in histology as in those OM triple treated patients in whom $H$ pylori eradication was successful.

\section{Symptoms, omeprazole dose, and endoscopic oesophagitis}

There were no significant changes in the severity of GORD symptoms in either treatment group during follow up, with median symptom scores of 0 and less than $10 \%$ prevalence of moderate to severe symptoms in both groups at all three visits (fig 4). The prevalence of any degree of reflux symptoms at the two year visit was $25 \%$ in the OM only group and $34 \%$ in the OM triple group $(p=0.15)$. There was no change in endoscopic signs of oesophagitis over time in 


\begin{tabular}{|c|c|c|c|c|c|c|}
\hline \multirow[b]{2}{*}{ Variable } & \multirow[b]{2}{*}{ Score } & \multicolumn{2}{|c|}{$\begin{array}{l}\text { OM only (by treatment } \\
\text { group) }\end{array}$} & \multicolumn{2}{|c|}{$\begin{array}{l}\text { OM triple (by treatment } \\
\text { group) }\end{array}$} & \multirow[b]{2}{*}{$p$ Value } \\
\hline & & Baseline & Last visit & Baseline & Last visit & \\
\hline \multirow[t]{4}{*}{ Activity } & None & 48 & 64 & 39 & 85 & \multirow[t]{4}{*}{$<0.001$} \\
\hline & Mild & 45 & 32 & 43 & 11 & \\
\hline & Moderate & 8 & 7 & 9 & & \\
\hline & Severe & 6 & 4 & 5 & & \\
\hline \multirow{4}{*}{ Inflammation } & None & 9 & 14 & 8 & 30 & \multirow{4}{*}{$<0.001$} \\
\hline & Mild & 63 & 49 & 53 & 59 & \\
\hline & Moderate & 30 & 37 & 30 & 7 & \\
\hline & Severe & 5 & 7 & 5 & & \\
\hline \multirow{4}{*}{ Atrophy } & None & 85 & 91 & 73 & 80 & \multirow[t]{4}{*}{0.953} \\
\hline & Mild & 17 & 12 & 16 & 9 & \\
\hline & Moderate & 3 & 2 & 4 & 2 & \\
\hline & Severe & 2 & 2 & 2 & 4 & \\
\hline \multirow{4}{*}{ Intestinal metaplasia } & None & 87 & 88 & 82 & 77 & \multirow[t]{4}{*}{0.278} \\
\hline & Mild & 13 & 15 & 7 & 13 & \\
\hline & Moderate & 5 & 2 & 5 & 3 & \\
\hline & Severe & 2 & 2 & 2 & 3 & \\
\hline \multirow[t]{4}{*}{ H pylori } & None & 41 & 67 & 37 & 89 & \multirow[t]{4}{*}{$<0.001$} \\
\hline & Mild & 46 & 18 & 38 & 5 & \\
\hline & Moderate & 7 & 6 & 7 & & \\
\hline & Severe & 13 & 16 & 14 & 2 & \\
\hline
\end{tabular}

either group during follow up. For both groups, erosive or ulcerative oesophagitis was present in less than $8 \%$ at the one and two year follow ups (fig 5).

The protocol allowed investigators to adjust the omeprazole dose according to the adequacy of the control of GORD. However, in both groups, the omeprazole dose required did not change over time. The mean daily dose in the OM only group was 26.1 (range 10-80) $\mathrm{mg}$ at baseline and 28.1 (range 10-120) mg at two years. In the OM triple group, the mean daily omeprazole dose was $26.7 \mathrm{mg}$ at baseline (range 10-80) and 29.0 (range 20-80) $\mathrm{mg}$ at two years ( $\mathrm{p}>0.20$ ) (fig 6).

\section{DISCUSSION}

Our study has provided important insights into the issues that relate to $H$ pylori infection, reflux disease, and its treatment. In contrast with previous studies, ours was randomised, prospective, double blind, well powered, and specifically designed to investigate issues concerning $H$ pylori infection and long term acid suppression in reflux disease. As such, it addressed the criticisms and concerns that were raised in previous studies such as in our initial cohort study. ${ }^{9}$ Interpretation of the gastric biopsies was made as uniform and objective as possible by the use of predefined criteria, and

\begin{tabular}{|c|c|c|c|c|c|c|}
\hline \multirow[b]{2}{*}{ Variable } & \multirow[b]{2}{*}{ Score } & \multicolumn{2}{|c|}{$\begin{array}{l}\text { OM only (H pylori + ve } \\
\text { patients at } 2 \text { y) }\end{array}$} & \multicolumn{2}{|c|}{$\begin{array}{l}\text { OM triple }(H \text { pylori - ve } \\
\text { patients at } 2 \text { y) }\end{array}$} & \multirow[b]{2}{*}{ p Value } \\
\hline & & Baseline & Last visit & Baseline & Last visit & \\
\hline \multirow[t]{4}{*}{ Activity } & None & 1 & 3 & 9 & 89 & $<0.001$ \\
\hline & Mild & 33 & 27 & 30 & 1 & \\
\hline & Moderate & 32 & 29 & 33 & & \\
\hline & Severe & 16 & 23 & 18 & & \\
\hline \multirow{4}{*}{ Inflammation } & None & & & 8 & 43 & $<0.001$ \\
\hline & Mild & 17 & 6 & 16 & 44 & \\
\hline & Moderate & 43 & 39 & 45 & 3 & \\
\hline & Severe & 22 & 37 & 21 & & \\
\hline \multirow{4}{*}{ Atrophy } & None & 58 & 60 & 66 & 80 & 0.001 \\
\hline & Mild & 14 & 11 & 11 & 7 & \\
\hline & Moderate & 6 & 6 & 11 & 3 & \\
\hline & Severe & 4 & 5 & 2 & & \\
\hline \multirow[t]{3}{*}{ Intestinal metaplasia } & None & 79 & 80 & 85 & 83 & 0.688 \\
\hline & Mild & 3 & 2 & 4 & 7 & \\
\hline & $\begin{array}{l}\text { Moderate } \\
\text { Severe }\end{array}$ & & & 1 & & \\
\hline \multirow[t]{4}{*}{$H$ pylori } & None & 3 & 2 & 6 & 90 & $<0.001$ \\
\hline & Mild & 19 & 18 & 29 & & \\
\hline & Moderate & 20 & 18 & 14 & & \\
\hline & Severe & 40 & 44 & 41 & & \\
\hline
\end{tabular}




\begin{tabular}{|c|c|c|c|c|c|c|}
\hline \multirow[b]{2}{*}{ Variable } & \multirow[b]{2}{*}{ Score } & \multicolumn{2}{|c|}{$\begin{array}{l}\text { OM only ( } H \text { pylori +ve } \\
\text { patients at } 2 \text { y) }\end{array}$} & \multicolumn{2}{|c|}{$\begin{array}{l}\mathrm{OM} \text { triple }(\mathrm{H} \text { pylori -ve } \\
\text { patients at } 2 \mathrm{y})\end{array}$} & \multirow[b]{2}{*}{ p Value } \\
\hline & & Baseline & Last visit & Baseline & Last visit & \\
\hline \multirow[t]{4}{*}{ Activity } & None & 29 & 40 & 32 & 78 & \multirow[t]{4}{*}{$<0.001$} \\
\hline & Mild & 38 & 29 & 38 & 6 & \\
\hline & Moderate & 6 & 7 & 9 & & \\
\hline & Severe & 6 & 3 & 5 & & \\
\hline \multirow{4}{*}{ Inflammation } & None & 4 & 3 & 8 & 30 & \multirow[t]{4}{*}{$<0.001$} \\
\hline & Mild & 45 & 34 & 46 & 51 & \\
\hline & Moderate & 25 & 35 & 25 & 3 & \\
\hline & Severe & 5 & 7 & 5 & & \\
\hline \multirow{4}{*}{ Atrophy } & None & 85 & 91 & 73 & 80 & \multirow{4}{*}{0.682} \\
\hline & Mild & 17 & 12 & 16 & 9 & \\
\hline & Moderate & 3 & 2 & 4 & 2 & \\
\hline & Severe & 2 & 2 & 2 & 4 & \\
\hline \multirow{4}{*}{ Intestinal metaplasia } & None & 61 & 64 & 72 & 68 & \multirow{4}{*}{0.113} \\
\hline & Mild & 13 & 12 & 7 & 11 & \\
\hline & Moderate & 3 & 2 & 3 & 3 & \\
\hline & Severe & 2 & 1 & 2 & 2 & \\
\hline \multirow{4}{*}{ Helicobacter pylori } & None & 31 & 39 & 33 & 84 & \multirow{4}{*}{$<0.001$} \\
\hline & Mild & 29 & 18 & 33 & & \\
\hline & Moderate & 7 & 6 & 6 & & \\
\hline & Severe & 12 & 16 & 12 & & \\
\hline
\end{tabular}

by blinded assessment of all biopsies by having one histopathologist very experienced in the field. The major findings of the present study were: (1) moderate to severe corpus gastritis is highly prevalent among $H$ pylori positive reflux disease patients who are receiving daily long term PPI therapy; (2) H pylori eradication results in healing of most of the gastritis, despite continued PPI therapy; and (3) there is no clinically significant adverse impact on the severity of reflux disease or its control by omeprazole in the two years following $H$ pylori eradication, during which time gastritis largely healed.

Colonisation of the gastric mucosa with $H$ pylori almost invariably causes chronic active gastritis. ${ }^{125}$ There is general agreement that acid suppressant therapy changes the usually antral predominant gastritis to one that is corpus predominant. ${ }^{67}$ The baseline data show that severe corpus gastritis is very prevalent in reflux disease patients who are $H$ pylori positive and receive PPI therapy. This finding should be a guide for a clinical management strategy. Overall, corpus gastritis activity was moderate in $35 \%$ and severe in $17 \%$, and chronic corpus inflammation was moderate in $25 \%$ and severe in $22 \%$. Corpus atrophy of any degree was present in $26 \%$, being moderate in $8.5 \%$ and severe in $4.3 \%$. These data show a substantial impact of $H$ pylori infection on the corpus mucosa in a high proportion of patients. This impact would be expected to become more severe over time, which is relevant as the average age of our patients was 62 years.

The pattern of gastritis seen during acid suppressant therapy is relevant as this pattern is associated with an increased risk for the development of gastric cancer, primarily as a result of progression to gastric atrophy, ${ }^{96}$ but also by itself without the presence of atrophy, as was shown in a recent longitudinal study. ${ }^{5}$ The present study was not designed to address the question of whether PPI therapy related changes in gastritis increase the rate of development of gastric atrophy or intestinal metaplasia. Review of the

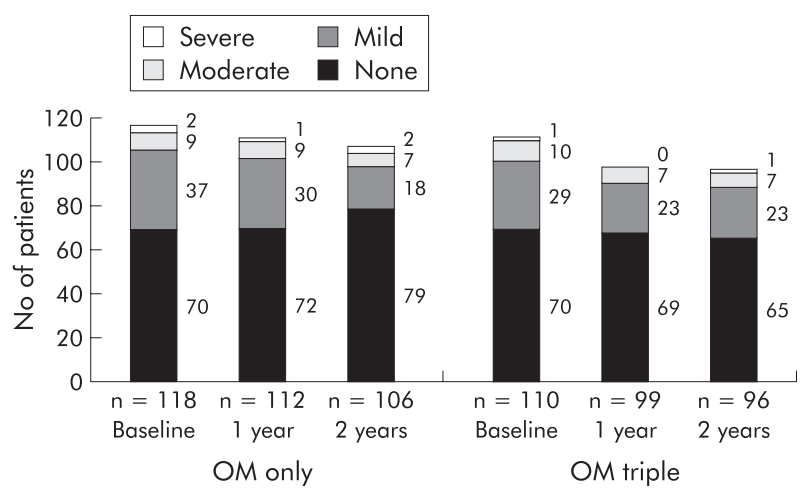

Figure 4 Overall reflux symptoms in patients randomly assigned to omeprazole alone (OM only) or to eradication triple therapy (OM triple). The bars represent the severity of reflux symptoms at baseline, and after one year and two years of follow up for the OM only and OM triple groups. The results are represented as actual numbers of patients (presented to the right of each bar segment).

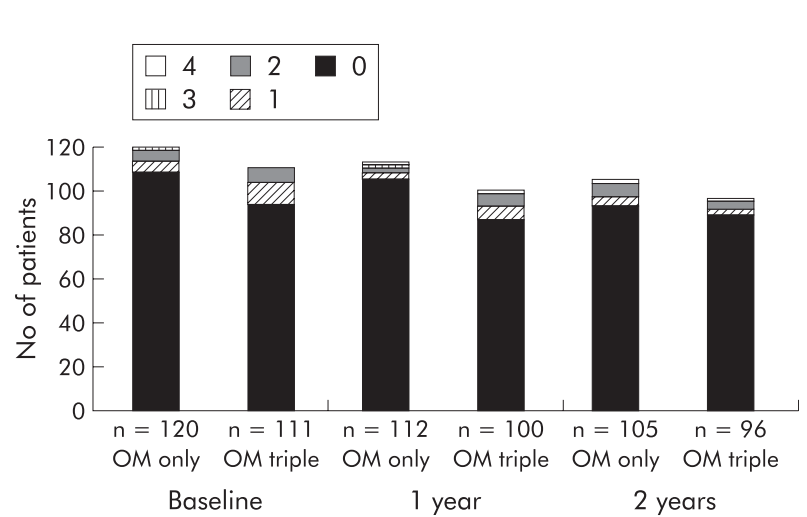

Figure 5 Grade of oesophagitis in patients randomly assigned to omeprazole alone (OM only) or to eradication triple therapy (OM triple). The bars represent the severity of grade of oesophagitis at baseline, and after one year and two years of follow up for the OM only and OM triple group. The results are represented as actual numbers of patients. 


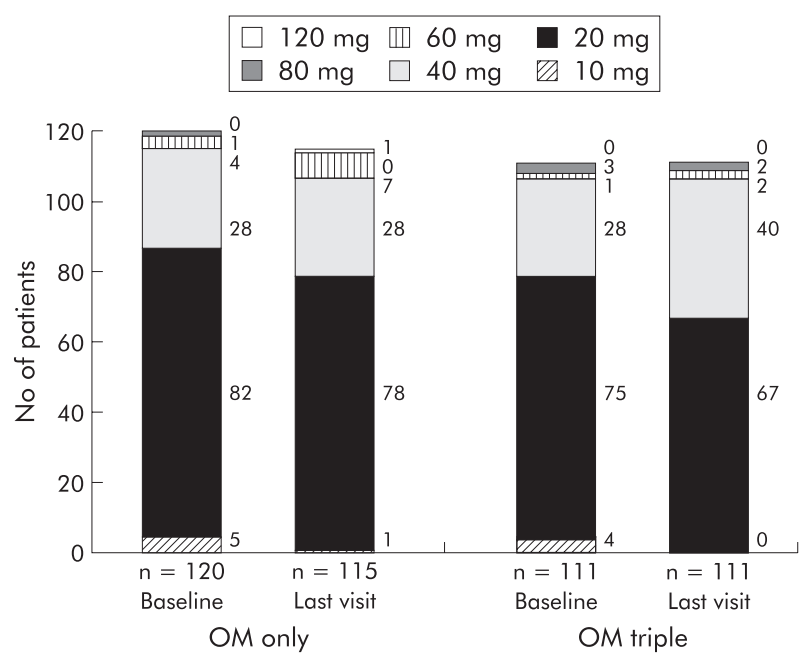

Figure 6 Omeprazole dose at baseline and at the last visit in patients randomly assigned to omeprazole alone (OM only) or to eradication triple therapy (OM triple). The bars represent the dose of omeprazole used to control gastro-oesophageal reflux disease at baseline, and after one year and two years of follow up for the OM only and OM triple groups. The results are represented as actual numbers of patients (presented to the right of each bar segment).

available data in 1996 led the US Food and Drug Administration to conclude that there were insufficient data to justify eradication of $H$ pylori in patients taking long term acid suppressant therapy, especially as there were then substantial theoretical concerns that eradication of $H$ pylori would make reflux disease more difficult to control. This concern has been largely allayed by recent data. Three recent randomised studies showed that $H$ pylori eradication did not affect the relapse rate of reflux disease either during ongoing PPI therapy ${ }^{16}$ or after withdrawal of such therapy. ${ }^{27} 28$

Previous studies show that $H$ pylori eradication leads to healing of gastritis within 12-24 months. Two randomised smaller studies have shown that when $H$ pylori is eradicated at the start of omeprazole maintenance therapy there is resolution of gastritis and prevention of the onset of a corpus predominant pangastritis. ${ }^{16}{ }^{17}$ The present study confirms these findings. Chronic active pangastritis persisted in patients who remained $H$ pylori positive but disappeared in most patients who received $H$ pylori eradication treatment.

Our study provides important insights into the effect of $H$ pylori eradication on glandular atrophy in patients receiving long term PPI therapy. Previously available data on the effect of $H$ pylori eradication on atrophic gastritis are limited and conflicting, most coming from uncontrolled cohort studies, usually with a limited sample size, short follow up periods, and unblinded suboptimal protocols for histological evaluation. ${ }^{29-38}$ Some of these studies have suggested that $H$ pylori eradication could lead to improvement in glandular atrophy and intestinal metaplasia, but others have not. Until now, there has been only one published randomised controlled study on this issue. ${ }^{39}$ The investigators followed $515 \mathrm{H}$ pylori positive Chinese subjects without specific conditions or therapy for one year after randomisation to either eradication treatment or placebo. In subjects who remained $H$ pylori positive, there was an increase in corpus glandular atrophy over one year. In subjects who became $H$ pylori negative, acute and chronic inflammation improved but the changes in glandular atrophy and intestinal metaplasia could not be evaluated adequately because of the small number of subjects with such lesions at baseline. We therefore followed our patients for two years and analysed the data according to treatment arm.
The overall prevalence of $H$ pylori associated corpus glandular atrophy in our study population was $26 \%$ at baseline. This is consistent with other data obtained in patients who had been using long term PPI therapy. ${ }^{9}{ }^{10}{ }^{12}$ In the OM only group, the prevalence of glandular atrophy did not change during the two years of observation (tables 4, 5). Progression of glandular atrophy has been observed in other studies in $H$ pylori infected patients with longer follow up during PPI maintenance therapy. ${ }^{9-12}$ The lack of evidence of progression of atrophy in the OM only group in our study can be explained by the relatively short two year follow up period of our study. Certainly, conditions that favour atrophy progression-persistent chronic active corpus gastritis-were present. The $95 \%$ confidence interval for the annual change in prevalence of atrophic gastritis over time ranged from $-9 \%$ to $+5 \%$. This wide interval fully includes the possibility for progression of atrophy, as previously observed, which means that our current data do not contrast with previous findings. ${ }^{1012}$ A longer follow up would have enabled calculation of a narrowed confidence limit but this was not the purpose of the study. It might be that further progression of atrophy would occur similar to that observed previously in other studies ${ }^{10}{ }^{12}$; it may also be that further development of atrophic gastritis would not occur as the changes have already been induced in susceptible individuals. The present study started with patients who at baseline had already used omeprazole for a mean of 5.3 years, whereas previous studies always followed patients from the start of PPI use and never had a longer mean follow up than approximately six years. ${ }^{12}$ In contrast with the observations in the OM only group, in the OM triple group the prevalence of glandular atrophy decreased. We can thus authoritatively confirm the observation of several smaller and uncontrolled case studies that $H$ pylori eradication can lead to restitution of gastric glands and regression of atrophy. This regression was not restricted to subjects with mild corpus atrophy but also occurred in patients with moderate and severe glandular atrophy (tables 2, 3).

It has been suggested that gland loss is often incorrectly diagnosed in patients with chronic active gastritis, as the inflammation may lead to a widening of the intraglandular space ${ }^{40}$ However, in most studies, including our own, the presence of glandular atrophy was determined by experienced and leading gastrointestinal pathologists ${ }^{10} 121741$ who used internationally accepted criteria. ${ }^{22}$ Furthermore, follow up of $H$ pylori positive GORD patients from the start of PPI therapy showed a markedly different time pattern for the evolution of corpus predominant pangastritis versus glandular atrophy, with the first occurring immediately and the second occurring within the following years. ${ }^{10} 12$ In the present study, regression of atrophy was also a more gradual process than resolution of active gastritis. These observations strongly and consistently support the hypothesis that inflammation and gland loss are different phenomena. This is further supported by quantitative histological studies on the effect of PPI treatment and $H$ pylori eradication in $H$ pylori positive GORD patients, ${ }^{42}$ as well as by functional studies showing an association of atrophy, but not of corpus predominant pangastritis, with hypergastrinaemia, ${ }^{43}$ and a decrease in serum pepsinogen I and vitamin Bl2. ${ }^{44}$ Restitution of glands after eradication is a remarkable phenomenon, which until now has been considered an unrealistic expectation. ${ }^{45}$ It is impossible by definition to blind the pathologist to the H pylori status of the slides under evaluation. There is therefore the potential for the results to be biased but this is unlikely to fully explain the marked results of $H$ pylori eradication on corpus gastritis and atrophy.

Our primary analysis followed the rigorous intention to treat approach of including data from all available study 
patients. The reported outcomes were influenced by the inevitable minority of patients in the OM triple group in whom triple therapy failed to eradicate $H$ pylori and by those in the OM only group who became $H$ pylori negative. Normally, if $H$ pylori eradication fails initially, the clinician would strive to eradicate the infection by retreatment. Our secondary analysis by $H$ pylori status gives a clearer picture of what can be achieved with $H$ pylori eradication, and emphasises how effectively gastritis is reversed despite continued omeprazole. $H$ pylori eradication in the OM only group in particular appeared to occur as a result of additional antibiotic treatment outside of the protocol, mainly for respiratory infection.

This study adds significantly to the growing evidence that overall, $H$ pylori eradication has a minimal impact on the clinical course of reflux disease and its therapy, ${ }^{16} 284647$ or may even lead to an improvement in symptoms. ${ }^{48}$ An exception to this generalisation is the experience from Japan and Hong Kong. ${ }^{49-51}$ In East-Asian countries, gastritis is frequently so severe that it suppresses acid secretion to a level that renders gastric juice relatively non-injurious to the oesophageal mucosa. It has been shown that in such patients, acid secretion recovers substantially following $H$ pylori eradication $^{52}$ and that this can lead to the development of reflux symptoms and generally mild oesophagitis in patients with previously subclinical symptoms from impairment of gastro-oesophageal competence. ${ }^{49-51}$ The structured two year follow up of patients in the present study showed no evidence of a clinically significant impact of $H$ pylori eradication on the efficacy of control of reflux disease by omeprazole, as assessed by symptoms, endoscopy, and dose of omeprazole required to control GORD. These data emphasise that the balance weighs heavily in favour of benefit from $H$ pylori eradication in $H$ pylori infected GORD patients. This is consistent with 24 hour oesophageal pH monitoring studies performed with or without acid suppressant therapy in which no differences were observed between $H$ pylori positive and negative reflux disease patients with respect to oesophageal acid exposure with or without suppressive therapy. ${ }^{53} 54$

In conclusion, our study has documented that in $H$ pylori colonised GORD patients on long term proton pump inhibitor therapy, eradication of $H$ pylori almost completely eliminates gastritis and may lead to regression of corpus glandular atrophy. This has no clinically significant adverse impact on the severity of reflux disease or its control by omeprazole. For these reasons, we believe that GORD patients who require long term PPI treatment should be tested for $H$ pylori infection and treated if positive.

\section{ACKNOWLEDGEMENT}

Supported by AstraZeneca R\&D, Sweden.

\section{Authors' affiliations}

E J Kuipers, Department of Gastroenterology and Hepatology, Erasmus MC University Medical Centre, Rotterdam, the Netherlands

G F Nelis, Department of Gastroenterology, Sophia Hospital, Zwolle, the Netherlands

E C Klinkenberg-Knol, Department of Gastroenterology, Free University Hospital, Amsterdam, the Netherlands

P Snel, Department of Gastroenterology, Slotervaart Hospital,

Amsterdam, the Netherlands

D Goldfain, Department of Gastroenterology, Hopital Victor Jusselin, Dreux, France

J J Kolkman, Department of Gastroenterology, Medical Spectrum Twente, Enschede, the Netherlands

H P M Festen, Department of Gastroenterology, Groot Ziekengasthuis, Den Bosch, the Netherlands

J Dent, Department of Gastroenterology, Royal Adelaide Hospital, Adelaide, Australia

P Zeitoun, Department of Gastroenterology, Hopital Robert Derbre, Reims, France
N Havu, AstraZeneca R\&D, Södertalje, Sweden M Lamm, A Walan, AstraZeneca R\&D, Mölndal, Sweden

Presented in part at the annual meeting of the American Gastroenterology Association, Atlanta, Georgia, 20-23 May 2001.

\section{APPENDIX}

\section{PARTICIPANTS}

\section{The Netherlands}

Amsterdam: EC Klinkenberg-Knol, Free University Medical Centre; EJ Kuipers, Free University Medical Centre, P Snel, Slotervaart Hospital; AAM Geraedts, Onze Lieve Vrouwe Gasthuis; Breda: CPM Dekkers, Amphia Hospital; Den Bosch: HPM Festen, Bosch Medicentrum; Den Haag: SDJ van der Werf, Medisch Centrum Haaglanden; Enschede: JJ Kolkman, Medisch Spectrum Twente; Haarlem: W Dekker, Kennemer Gasthuis; Leiden: CBHW Lamers, Leiden University Medical Centre; Nijmegen: JBMJ Jansen, Universitair Medisch Centrum St Radboud; Rotterdam: HSLM Tjen, Sint Fransiscus Gasthuis; RJTh Ouwendijk, Ikazia Hospital; Sittard: LGJB Engels, Maaslandziekenhuis; Zwijndrecht: R Beukers, Albert Schweitzer Ziekenhuis; Zwolle: GF Nelis, Isala Klinieken, loc. Sophia; BE Schenk, Isala Klinieken, loc. De Weezenlanden; BD Westerveld, Isala Klinieken, loc. Sophia.

\section{France}

Creteil: J C Delchier, Hopital Henri Mondor; Dreux: D Goldfain, Centre Drouais d'Hepato-gastroenterologie; Forbach: D Schmitz, Hopital Marie Madeleine; Freyming: A Laugros, Hopital de Freyming SSM; Paris: S Chaussade, Hopital Cochin; M Mignon, Chu Bichat, Service de Gastroentérologie; Reims: P Zeitoun, Hopital Robert Debre; Rouen: R Colin, Hopital Charles Nicolle; Toul: E M Protte, 18 Rue Gambetta; Toulouse: J Escourrou, Hopital de Ranguiel; Vandouvre: M Bigard, Hopital Brabois.

\section{UK}

Leeds: A Patel, 3 The Coppice; Leigh: M Cottrill, Brook Mill Medical Centre; Oldbury: K Holtom, The Health Centre; Poulton: F Costello, Wilkinson Way; Sheffield: P Hardy, Norwood Medical Centre; Stoke-on-Trent: R Page, Audley Health Centre; S Rabie, Kidsgrove Medical Centre.

\section{Denmark}

Odense: K Lauritsen, Odense Universitetshospital.

\section{Sweden}

Gävle: P Unge, Country Hospital Sandviken-Gävle; Gothenburg: L Lundell, Sahlgrenska Hospital.

\section{Australia}

Adelaide: J Dent, Royal Adelaide Hospital; Bedford Park: G Young, Flinders Medical Centre; Launceston: B Mitchell, Launceston General Hospital.

\section{Germany}

Fulda: D Jaspersen, Städt Klinikum Fulda.

\section{REFERENCES}

1 Kuipers EJ, Uyterlinde AM, Peña AS, et al. Long term sequelae of Helicobacter pylori gastritis. Lancet 1995;345:1525-8.

2 Ekstrom AM, Held M, Hansson L-E, et al. Helicobacter pylori in gastric cance established by CagA immunoblot as a marker of past infection. Gastroenterology 2001;121:784-91.

3 Correa P. Human gastric carcinogenesis: a multistep and multifactorial process. Cancer Res 1992;52:6735-40.

4 Sipponen P, Kekki M, Haapakoski J, et al. Gastric cancer risk in chronic atrophic gastritis: statistical calculations of cross-sectional data. Int J Cancer 1985; $35: 173-7$

5 Uemura N, Okamoto S, Yamamoto S, et al. Helicobacter pylori infection and the development of gastric cancer. N Engl J Med 2001;345:784-9.

6 Logan RPH, Walker MM, Misiewicz JJ, et al. Changes in the intragastric distribution of Helicobacter pylori during treatment with omeprazole. Gut 1995;36:12-16.

7 Kuipers EJ, Uyterlinde AM, Peña AS, et al. Increase of Helicobacter pylori associated corpus gastritis during acid suppressive therapy: Implications for long-term safety. Am J Gastroenterol 1995;90:1401-6. 
8 Klinkenberg-Knol EC, Festen HPM, Jansen JBMJ, et al. Efficacy and safety of long-term treatment with omeprazole for refractory reflux esophagitis. Ann Intern Med 1994;121:161-7.

9 Kuipers EJ, Lundell L, Klinkenberg-Knol EC, et al. Atrophic gastritis and Helicobacter pylori infection in patients with reflux esophagitis treated with omeprazole or fundoplication. N Engl J Med 1996;334:1018-22.

10 Lundell L, Miettinen P, Myrvold HE, et al. Lack of effect of acid suppression therapy on gastric atrophy. Gastroenterology 1999;117:319-26.

11 Eissele R, Brunner G, Simon B, et al. Gastric mucosa during treatment with lansoprazole: Helicobacter pylori is a risk factor for argyrophil-cell hyperplasia. Gastroenterology 1997; 112:707-17.

12 Klinkenberg-Knol EC, Nelis F, Dent J, et al. Long-term omeprazole treatment in resistant gastroesophageal reflux disease: efficacy, safety and influence on gastric mucosa. Gastroenterology 2000;118:661-9.

13 Berstad AE, Hattlebak JG, Maartman-Moe H, et al. Helicobacter pylori gastritis and epithelial cell proliferation in patients with reflux oesophagitis after treatment with lansoprazole. Gut 1997;41:740-7.

14 Lamberts R, Brunner G, Solcia E. Effects of very long (up to 10 years) proton pump blockade on human gastric mucosa. Digestion 2001;64:205-13.

15 Malfertheiner P, Megraud F, O'Morain C, et al. Current concepts in the management of Helicobacter pylori infection - the Maastricht 2-2000 consensus report. Aliment Pharmacol Ther 2002;16:167-80.

16 Schenk BE, Kuipers EJ, Nelis GF, et al. Effect of Helicobacter pylori eradication on chronic gastritis during omeprazole therapy. Gut 2000;46:615-21

17 Moayyedi P, Wason C, Peacock R, et al. Changing patterns of Helicobacter pylori gastritis in long-standing acid suppression. Helicobacter 2000:5:206-14.

18 Savary M, Miller G. The oesophagus: handbook and atlas of endoscopy, Solothurn, Switzerland, Grassman, 1987.

19 Garvey W, Fathi A, Bigelow F. Modified Steiner for the demonstration of spirochetes. J Histotechnol 1985:8:15-17.

20 Sevier AC, Munger BL. Technical note: a silver method for paraffin sections of neural tissue. J Neuropathol Exp Neurol 1965;24:130-5.

21 Grimelius L, Wilander E. Silver stains in the study of endocrine cells of the gut and pancreas. Invest Cell Pathol 1980;3:3-12.

22 Dixon MF, Genta RM, Yardley JH, et al. Classification and grading of gastritis. The up-dated Sydney system. Am J Surg Pathol 1996;20:1161-81.

23 Solcia E, Bordi C, Creutzfeldt W, et al. Histopathological classification of nonantral gastric endocrine growth in man. Digestion 1988;41:185-200.

24 Armitage P, Berry G. Statistical methods in medical research, 2nd ed. London: Blackwell Scientific Publications, 1990.

25 Dooley CP, Cohen H, Fitzgibbons PL, et al. Prevalence of Helicobacter pylori infection and histologic gastritis in asymptomatic persons. N Engl J Med 1989;321:1562-6

26 Meining A, Bayerdörffer E, Müller $P$, et al. Gastric carcinoma risk index in patients infected with Helicobacter pylori. Virchow Arch 1998:432:311-14.

27 Schwizer W, Thumshirn M, Dent J, et al. Helicobacter pylori and symptomatic relapse of gastro-oesophageal reflux disease: a randomised controlled trial. Lancet 2001;357:1738-42.

28 Moayyedi P, Bardhan C, Young L, et al. Helicobacter pylori eradication does not exacerbate reflux symptoms in gastro-esophageal reflux disease. Gastroenterology 2001;121:1120-6.

29 van der Hulst RWM, van der Ende A, Dekker FW, et al. Effect of Helicobacter pylori eradication on gastritis in relation to cagA: a prospective 1-year followup study. Gastroenterology 1997;113:25-30.

30 Satoh K, Kimura K, Taniguchi Y, et al. Biopsy sites suitable for the diagnosis of Helicobacter pylori infection and the assessment of the extent of atrophic gastritis. Am J Gastroenterol 1998;93:569-73.

31 Oberhuber G, Wuendisch T, Rappel S, et al. Significant improvement of atrophy after eradication therapy in atrophic body gastritis. Pathol Res Pract 1998; 194:609-13.

32 Tucci A, Biasco G, Paparo GF. Effect of eradication of Helicobacter pylori in patients with fundic atrophic gastritis. N Engl J Med 1997;336:957-8.

33 Stolte M, Meier E, Meining A. Cure of autoimmune gastritis by Helicobacter pylori eradication in a 21 -year old male. Z Gastroenterol 1998;36:641-3.
34 Larkin CJ, Watson P, Sloan JM, et al. Gastric corpus atrophy following eradication of Helicobacter pylori. Eur J Gastroenterol Hepatol 2001;13:377-82

35 Zerbib F, Lenk C, Sawan B, et al. Long-term effects of Helicobacter pylori eradication on gastric antral mucosa in duodenal ulcer patients. Eur J Gastroenterol Hepatol 2000;12:719-25.

36 Annibale B, Aprile MR, D'Ambra G, et al. Cure of Helicobacter pylori infection in atrophic body gastritis patients does not improve mucosal antrophy but reduces hypergastrinemia and its related effects on body ECL-cell hyperplasia. Aliment Pharmacol Ther 2000;14:625-34

37 Morales TG, Sampliner RE, Camargo E, et al. Inability to noninvasively diagnose gastric intestinal metaplasia in Hispanics or reverse the lesion with Helicobacter pylori eradication. J Clin Gastroenterol $2001 ; 32: 400-4$.

38 Ohkusa T, Fujiki K, Takashimizu I, et al. Improvement in atrophic gastritis and intestinal metaplasia in patients in whom Helicobacter pylori was eradicated. Ann Intern Med 2001;134:380-6.

39 Sung JJ, Lin SR, Ching JY, et al. Atrophy and intestinal metaplasia one year after cure of $\mathrm{H}$ pylori infection: a prospective, randomized study. Gastroenterology 2000;119:7-14.

40 Genta RM. Acid suppression and gastric atrophy: sifting fact from fiction. Gut 1998;43(suppl 1):S35-8.

41 Stolte M, Meining A, Schmitz JM, et al. Changes in Helicobacter pyloriinduced gastritis in the antrum and corpus during 12 months of treatment with omeprazole and lansoprazole in patients with gastro-oesophageal reflux disease. Aliment Pharmacol Ther 1998;12:247-53.

42 van Grieken NC, Meijer GA, Weiss MM, et al. Quantitative assessment of gastric corpus atrophy in subjects using omeprazole: a randomized follow-up study. Am J Gastroenterol 2001;96:2882-6.

43 Schenk BE, Kuipers EJ, Klinkenberg-Knol EC, et al. Hypergastrinemia during long-term omeprazole therapy: influences of vagal nerve function, gastric emptying and Helicobacter pylori infection. Aliment Pharmacol Ther 1998;12:605-12.

44 Schenk BE, Kuipers EJ, Klinkenberg-Knol EC, et al. Atrophic gastritis during long-term omeprazole therapy affects serum vitamin B12 levels. Aliment Pharmacol Therap 1999;13:1343-6.

45 Dixon MF. Prospects for intervention in gastric carcinogenesis: reversibility of gastric atrophy and intestinal metaplasia. Gut 2001;49:2-4

46 McColl KE, Dickson A, El-Nujumi A, et al. Symptomatic benefit 1-3 years after Helicobacter pylori eradication in ulcer patients: impact of gastroesophageal reflux disease. Am J Gastroenterol 2000;95:101-5.

47 Rokkas T, Ladas SD, Liatsos C, et al. Effectiveness of acid suppression in preventing gastroesophageal reflux disease (GERD) after successful treatment of Helicobacter pylori infection. Dig Dis Sci 2001;46:1567-72.

48 Chiba N, Veldhuyzen van Zanten SJO, Sinclair P, et al. Treating Helicobacter pylori infection in primary care patients with uninvestigated dyspepsia: the Canadian adult dyspepsia empiric treatment-Helicobacter pylori positive (CADET-Hp) randomised controlled trial. BMJ 2002;324:1012-16.

49 Koike T, Ohara S, Sekine H, et al. Increased gastric acid secretion after Helicobacter pylori eradication may be a factor for developing reflux disease. Aliment Pharmacol Ther 2001;15:813-20.

50 Hamada $\mathrm{H}$, Haruma K, Mihara $M$, et al. High incidence of reflux oesophagitis after eradication therapy for Helicobacter pylori: impacts of hiatal hernia and corpus gastritis. Aliment Pharmacol Ther 2000;14:729-35.

51 Wu JC, Chan FK, Wong SK, et al. Effect of Helicobacter pylori eradication on oesophageal acid exposure in patients with reflux oesophagitis. Aliment Pharmacol Ther 2002; 16:545-52.

52 Ruiz B, Correa P, Fontham ETH, et al. Antral atrophy, Helicobacter pylori colonization, and gastric pH. Am J Clin Pathol 1996;105:96-101.

53 Peters FTM, Kuipers EJ, Ganesh S, et al. The influence of Helicobacter pylori on oesophageal acid exposure in GERD during acid suppressive therapy. Aliment Pharmacol Ther 1999;13:921-6.

54 Tefera S, Hattlebak JG, Berstad A. The effect of Helicobacter pylori eradication on gastro-oesophageal reflux. Aliment Pharmacol Ther $1999 ; 13: 915-20$

\section{GI SNAPSHOT}

\section{Answer}

From question on page 4

A detailed interview disclosed her habit of finger evacuation of the rectum. A diagnosis of self inflicted rectal ulcer was suspected. Avoidance of rectal digitation was advised. Follow up colonoscopy showed that the ulcer had healed, indicating that self inflicted injury was the aetiology.

Rectal ulcer is an infrequent pathology associated with various disorders, including inflammatory bowel disease, infectious proctitis, mucosal prolapse syndrome (MPS), ischaemic colitis, and neoplasms. Symptoms of MPS may include a sense of incomplete rectal evacuation necessitating digital manipulation. Therefore, in addition to the pathological examination, detailed history is very important to differentiate self inflicted rectal ulcer, especially from MPS. Enquiry about finger evacuation may be better asked without the presence of patients' family members or other medical staff. In conclusion, with an emphasis of the importance of detailed history, self inflicted rectal ulcer should be recognised as an important differential diagnosis for the management of anorectal diseases. 